\title{
El MUNDO FUNERARIO EN LA CIUDAD ROMANA DE ONOBA: LAS MANIFESTACIONES ARQUITECTÓNICAS DE LA NECRÓPOLIS NORTE $^{1}$
}

\author{
Lucía Fernández Sutilo \\ Juan M. Campos Carrasco \\ Nuria de la O Vidal Teruel \\ Universidad de Huelva
}

\section{RESUMEN}

En el presente artículo se presenta el paisaje funerario de la necrópolis norte de Onoba, articulado en torno a una serie de construcciones monumentales de carácter público y privado dispuestas a lo largo de una de las principales vías de acceso a la ciudad con el fin de servir de escaparate de representatividad ante propios y ajenos.

\section{Palabras Clave}

Necrópolis, Recintos Funerarios, Sepulturas, Vía Sepulcral, Onoba.

\section{ABSTRAC}

In the present article it is a question of the architectural landscape of Onoba's north necropolis. This one would be articulated around a series of monumental constructions of public and private character arranged along one of the principal exit ramps to the city.

\section{KEYWORDS}

Cementery, Funeral Enclosures, Graves, Sepulchral Route, Onoba

1 Este artículo se inscribe dentro del Proyecto de Investigación "Funus Onobense: el mundo funerario romano en el occidente de la Baetica" (Ministerio de Ciencia e Innovación. Referencia HAR 204; 23247), perteneciente al Plan Nacional de I+D+I en el marco del Plan Nacional de I+D+I (2008-2011), bajo la dirección del Prof. Dr. Juan M. Campos Carrasco. Igualmente se enmarca dentro del Subproyecto de Investigación I2TEP “MORSUDES”, liderado por la Universidad de Huelva, recibe apoyo de la Unión Europea y cofinanciación del Programa Operativo de Cooperación Transfronteriza España-Portugal a través del Fondo Europeo de Desarrollo Regional bajo la dirección del Prof. Dr. Juan M. Campos Carrasco. 


\section{INTRODUCCIÓN}

A pesar de la importancia que el mundo de los muertos tuvo para la población en época romana, las intervenciones arqueológicas desarrolladas sobre este tipo de patrimonio no han pasado en el caso de Huelva de simples informes y memorias en las que se incluyen listados interminables de ajuares y restos óseos, sin que se haya intentado avanzar desde ese análisis microespacial basado en la estructura o la pieza en sí, a uno macroespacial del cual trascender desde las creencias individuales hacia representaciones de la identidad colectiva como podían ser la existencia de sentimientos de etnicidad, el grado de adhesión de la población a la causa romana, así como la manera en la que se afrontaron los cambios políticos, económicos y sociales acontecidos en cada momento.

Es por ello que a partir de este artículo pretendemos plantear un primer acercamiento a las creencias funerarias de Onoba, ciudad que estaría definida por un fuerte sincretismo poblacional del que emanaría una cultura funeraria híbrida.

\section{NeCRÓPOLIS NORTE ${ }^{1}$}

Esta necrópolis estuvo ubicada en su día en torno a una de las principales vías de acceso a la ciudad, concretamente la que unía la zona minera y la campiña con la ciudad de Onoba y el puerto, con una ocupación diacrónica comprendida entre el siglo II a. C. y al menos mediados del siglo IV d. C. (Fig. 1).

1 Esta área cementerial ha sido objeto de diferentes intervenciones arqueológicas a cargo de diversos equipos de investigación. Concretamente, la primera de ellas desarrollada durante los primeros años de la década de los años 70 (Amo, 1976), pondría al descubierto parte de los enterramientos bajoimperiales de esta necrópolis. Décadas más tarde, en el solar colindante al anterior, se ejecutarían 7 fases distintas de intervención a cargo de dos equipos diferentes de arqueólogos entre los años 20002007 , merced a las cuales se conocería la evolución estratigráfica y constructiva de esta necrópolis desde época republicana hasta la bajoimperial (Gómez et alii, 2002: Inédito; De Haro, López y Castilla, 2007, Inédito y De Haro, Castilla y López, 2004, Inédito). De manera simultánea se llevarían a cabo dos nuevas excavaciones en sendos solares ubicados algo más hacia el sur, la primera de ellas en la c/ San Andrés n 5 y Plácido Bañuelos n ${ }^{\circ} 4-6$ (García y Delgado, 2001), donde se detectaría parte de una construcción funeraria no identificada como tal por su excavador, y una segunda en la Plaza San Pedro no publicada salvo el pertinente informe del anuario (González y Guerrero, 2008: Inédito y - González, Guerrero y Echevarría, 2006), donde sólo parte de las construcciones del cambio de Era serían relacionadas con el mundo funerario, quedando el resto vinculadas a un ámbito doméstico con el cual discrepamos como expondremos a continuación.
A diferencia de otras ciudades como las de Corduba, Baelo Claudia, Tarraco u Ostia Antica donde probablemente los enterramientos de época republicana fueron amortizados por el propio crecimiento de la ciudad (Vaquerizo, 2002a,150), las primeras evidencias funerarias de Onoba datan del siglo II a. C., posiblemente porque a la llegada de los primeros colonos romanos, éstos se encontraron con una ciudad amurallada desde época protohistórica, lo que favorecería que desde época republicana hasta la bajoimperial se perpetuara el uso funerario de los terrenos próximos al lienzo murario.

A este respecto, las manifestaciones funerarias iniciales llegadas hasta nosotros hablan de un conjunto de sepulturas de incineración practicadas directamente sobre el suelo, acompañadas por una serie de restos materiales procedentes de la celebración de la propia liturgia funeraria, así como a su uso posterior $^{2}$, junto a las cuales se localizaría un paramento asociado a una gran cantidad de nódulos de carbón, fragmentos de metal, malacofauna, restos óseos, opus signinum, una moneda de bronce (De Haro, López y Castilla, 2007, Inédito; De Haro, Castilla y López, 2004, Inédito; González y Guerrero, 2008: Inédito), así como variadas piezas cerámicas fechadas entre los siglos II-I a. C. - Fig. 2-. A pesar de lo escueto de esta información, el hecho de que el único uso constatado en este extremo de la ciudad se circunscriba al ámbito funerario, nos lleva a plantear la posibilidad de que esta construcción formase parte de algún tipo de recinto sepulcral, basándonos para ello tanto en las evidencias materiales anteriormente descritas, como en la presencia de este tipo de construcciones en las provincias occidentales del Imperio desde finales del siglo II a. C. (Hesberg, 1994, 73-ss), caso de la estructura constatada bajo uno de los monumentos de Puerta de Gallegos en Corduba de la primera mitad del siglo I a. C., consistente en la planta de un edificio rectangular al que se asociaban importantes restos correspondientes a los desechos de los banquetes funerarios celebrados en su interior, concretamente fragmentos de ánforas, copas de ce-

2 A pesar de que las sepulturas de la Plaza Ivonne Cazenave y San Pedro presentan las mismas características, éstas últimas se recogen en la memoria bajo la denominación de manchas de combustión u hogares. Este hecho nos genera bastantes reservas de cara a la identificación de estas unidades con una sepultura o bien con una hoguera ritual, lo que sin embargo no explica su vinculación con hogares dispersos a lo largo de un espacio extramuros ocupado, entre otras construcciones, por una sepultura monumental de planta circular. 

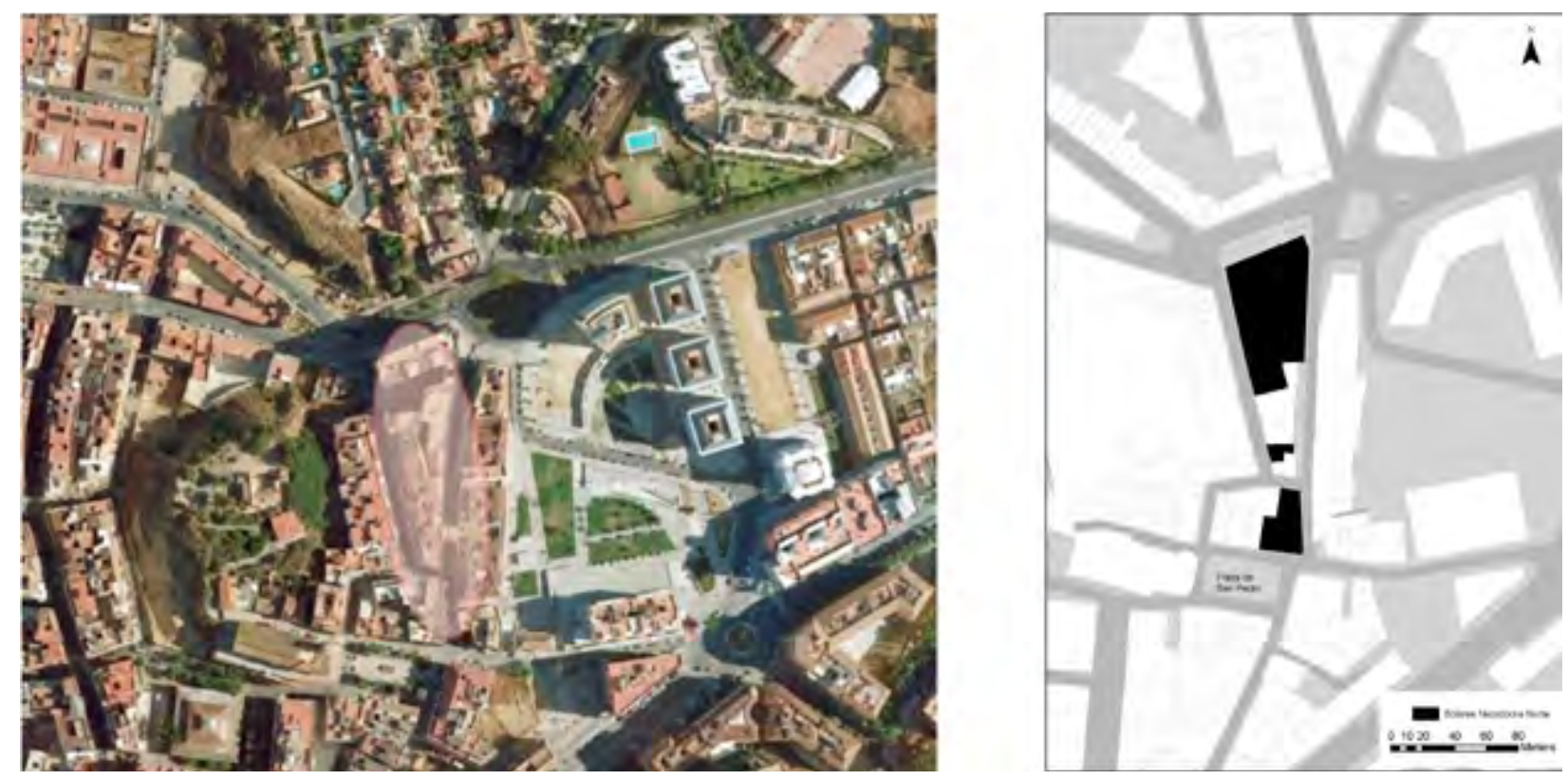

Fig. 1. Localización de la necrópolis norte de Onoba.

rámica campaniense y huesos quemados de ovicápridos y suidos, todos ellos mezclados con cenizas y carbón vegetal (Murillo y Carrillo, 1999, 369)3.

Hacia mediados del siglo I a. C., este paisaje funerario se vería sustancialmente modificado a consecuencia de las transformaciones experimentadas en los patrones socioeconómicos y políticos de la ciudad, motor de desarrollo de un intenso programa arquitectónico destinado a ensalzar el poder de la misma a partir de la imagen externa ofrecida por sus necrópolis. Paralelos de este despegue edilicio se documentan en otras ciudades del sureste hispánico, concretamente en Corduba y varias poblaciones localizadas en el alto Guadalquivir como Castulo, Iliturgi, Salaria, Ossigi, Tucci y Urgavo, donde el proceso de colonización/municipalización emprendido por Roma ante el interés de controlar y administrar las riquezas mineras favoreció la planificación de grandes empresas constructivas destinadas a la monumentalización de las principales vías funerarias, sufragadas por una importante oligarquía local que importaría los modelos sepulcrales itálicos de época tardorepublicana (Beltrán, 2000, 114 y 2002, 233- ss., Ruiz, 2005, 80).

3 En cualquier caso, la falta de intervenciones en la zona intermedia de esta necrópolis limita nuestro conocimiento de esta fase a los dos sectores que con casi toda probabilidad marcaron el inicio y el final de ésta, que no son otros que los enclavados en la Plaza San Pedro n ${ }^{0} 4-5$ y en la Plaza Ivonne Cazenave.

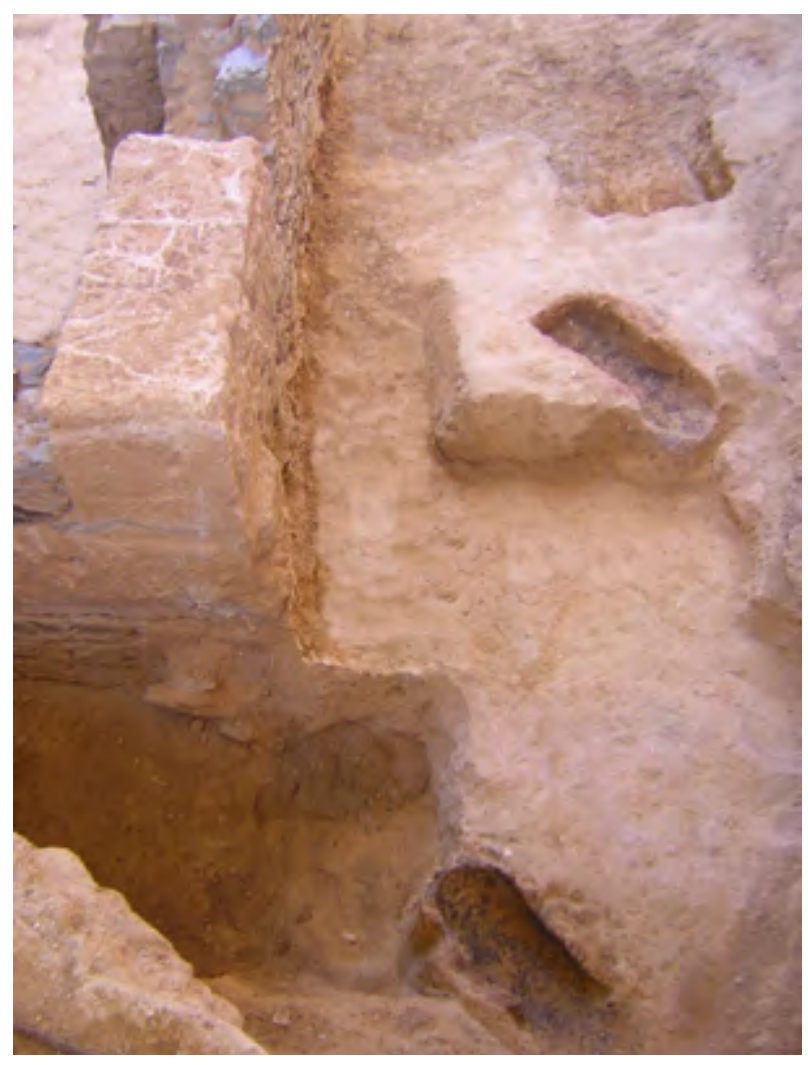

Fig. 2. Tumbas republicanas practicadas en la Plaza Ivonne Cazenave. 


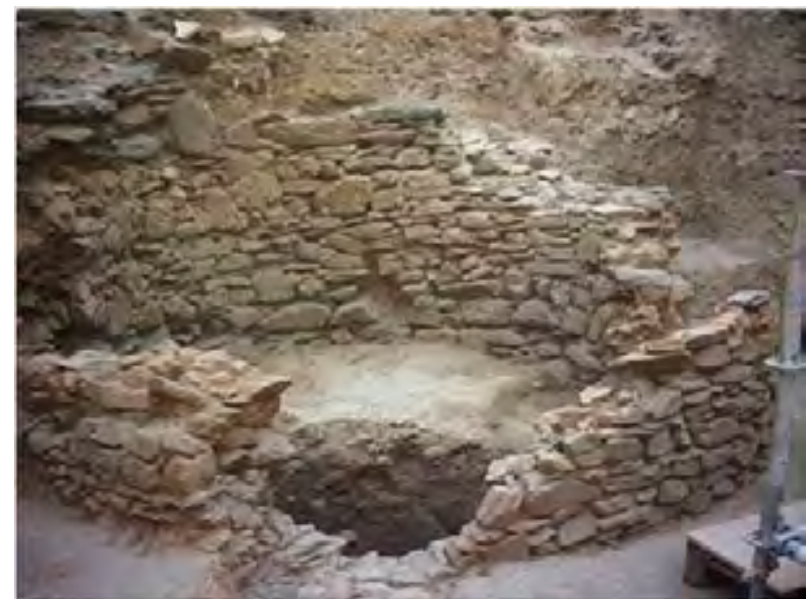

Fig. 3. Monumento sepulcral de planta circular de la Plaza San Pedro.

Precisamente en esta línea, pero en el extremo occidental de la provincia Baetica, se enmarcaría el programa edilicio desarrollado en la ciudad de Onoba, pues a pesar de la clara diferencia cultural y urbanística existente entre ambos ámbitos territoriales, la importancia de las minas de Sierra Morena, y por ende del puerto de la ciudad como enclave de comercialización de los productos mineros, agrícolas y pesqueros, supondría la puesta en marcha de un importante proceso de control por parte del Estado que culminaría probablemente con la consecución del estatuto de colonia latina en época augustea (Campos, Vidal y Ruiz, 2010, 67).

Dentro de este programa, la construcción que por antonomasia destacaría en esta necrópolis durante época altoimperial sería el edificio sepulcral de planta circular localizado en el solar de la Plaza San Pedro (Fig. 3), sin duda un claro referente dentro de este espacio funerario dado que a su ubicación

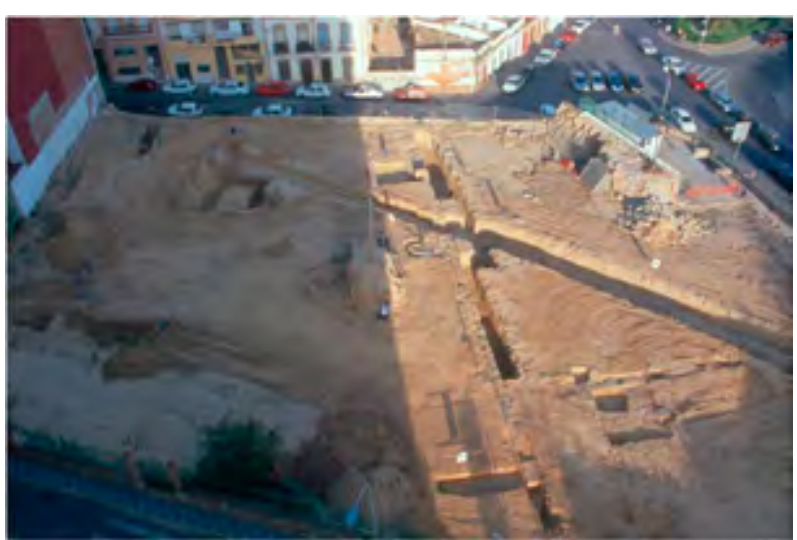

Fig. 4. Panorámica de excavación del interior del acotado imperial. justo a la salida de la ciudad, debemos unirle una fisonomía monumental acorde a la de los numerosos edificios de cuerpo cilíndrico de menos de $7 \mathrm{~m}$ de diámetro que florecieron por toda la Península Itálica durante el siglo I d. C. (Sacchi, 2003, 157), precisamente tras la elección de Augusto de esta tipología monumental como sepultura (Zanker, 1992; Vaquerizo, 2002a, 181).

En este caso, los restos conservados han permitido conocer una estructura circular de 3,6m de diámetro por $2,5 \mathrm{~m}$ de altura conservada, para cuya construcción se empleó el opus incertum, intercalando mampuestos de pizarra con ladrillos, sillarejos de calcarenita, tégulas y mortero de cal, todos ellos dispuestos en tongadas más o menos regularizadas y perfectamente careadas (González y Guerrero, 2008, Inédito). Al interior, su cámara funeraria gozó de una mayor majestuosidad gracias al revestimiento de todas sus paredes mediante mortero de cal con pintura roja, coronada por una cúpula de opus signinum asentada sobre una aproximación de hiladas de lajas de pizarra (González y Guerrero, 2008, Inédito). En ella, el rito empleado debió ser el de la cremación ${ }^{4}$, si bien la falta de documentación impide conocer si se practicó uno o varios enterramientos, ofreciendo en su lugar una intensa actividad ritual definida por un suelo con importantes manchas de adobe y tierras rubefactadas asociadas a carbones, restos óseos, vidrios, malacofauna y variado material cerámico. Sobre él sería depositado a modo de ofrenda una lucerna Dressel 15 con decoración en bajorrelieve de dos figuras humanas portando una jarra junto a lo que parece una especie de altar, una moneda frustra y un ánfora Beltrán II prácticamente completa (González y Guerrero, 2008, Inédito).

La construcción de esta tumba debió ser acometida hacia el cambio de Era, probablemente en época tiberiana, cuando el crecimiento económico de la ciudad permitió la edificación de este tipo de estructuras promocionadas por la élite local, en uso hasta su expolio y amortización a comienzos del

4 Aunque sus investigadores defienden la dualidad de ritos en su interior, algo que como veremos se encuentra constatado en otros sectores de la necrópolis, creemos que las evidencias al respecto de la existencia de una inhumación resultan insuficientes, ya que sólo se cuenta con un fragmento óseo adherido a la lucerna, el cual además de ser ínfimo, bien pudo adherirse durante la propia cremación, los banquetes funerarios realizados con posterioridad, e incluso pertenecer a un animal consumido durante los mismos. 
siglo II d. C. Esta misma situación se experimentaría en otras ciudades como la de Tarraco, donde el crecimiento económico favoreció el desarrollo de una élite local que comenzó a sufragar los primeros mausoleos y recintos (Ciurana y Macías, 2010, 329).

Enfrentado a este sepulcro se articuló un conjunto de tres recintos funerarios de opus incertum, con una vida funcional comprendida entre el cambio de Era y finales del siglo I d. C. destinados a la deposición de enterramientos de cremación directamente sobre el suelo ${ }^{5}$. Como norma general, los tres poseen unas dimensiones superiores a la media constatada en Hispania, donde estos edificios rondaron entre los $10 / 20$ pies in fronte (de 3 a $6 \mathrm{~m}$ ), por $8 / 20$ pies in agro (de 2,40 a $6 \mathrm{~m}$ ), para aproximarse en su lugar a las dimensiones constatadas en ciudades como Bolonia (10/30 pies in fronte e in agro) o Sarsina (18/20 pies in fronte), donde la existencia de una presión urbanística menor a la de otras ciudades como Corduba o Roma, hizo que el suelo funerario fuese un bien abundante, y por tanto de menor coste económico de cara a la existencia de grandes edificios (Rodríguez, 1991, 74).

No obstante a pesar de la magnificencia y el privilegio del que debió gozar esta área cementerial, así como los individuos allí sepultados, ésta se vería amortizada con motivo de la revalorización urbanística de este suburbia en época altoimperial mediante la construcción de una zona industrial a finales del siglo I d. C., optándose por el desmantelamiento conjunto de todas las estructuras, en un intento por borrar de la memoria colectiva una imagen funeraria convertida ya en pasado. Si bien, este fenómeno no resulta exclusivo de Onoba, de hecho en otras ciudades hispanas como Corduba, la construcción de numerosos vici junto a las principales vías de acceso a la ciudad en época flavia supondrían la amortización de importantes sectores funerarios (Vaquerizo, 2002a, 151), algunos de cuyos monumentos fueron desmontados, tapados o incluso integrados en las nuevas construcciones (Vaquerizo y Murillo, 2010, 476). Igualmente, en Emerita Augusta los importantes cambios urba-

5 Estos recintos se identifican en la memoria con diversas habitaciones y un patio central correspondientes a una casa de época romana, en cuyo interior se encontrarían diferentes manchas de combustión y hogares, en algunos de los cuales, además de material cerámico y restos óseos, aún se conservaban los listones de madera dispuestos en perpendicular (González y Guerrero, 2008, Inédito).

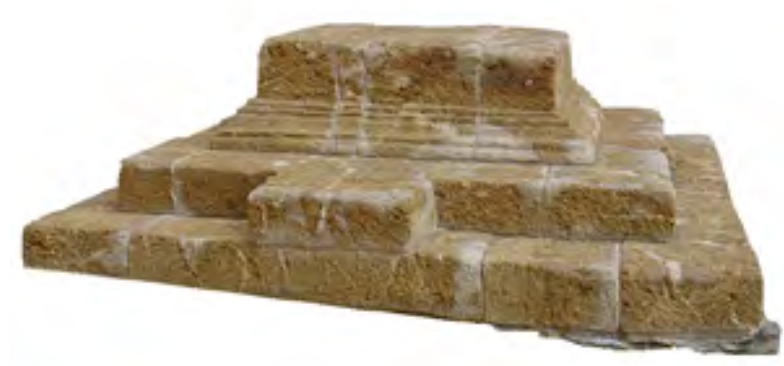

Fig. 5. Monumento escalonado de sillares.

nísticos generados ante la necesidad de crecimiento de la ciudad conllevaron la anulación de las áreas funerarias más próximas a sus murallas, destacando el caso de los Columbarios, amortizados por el propio vertedero de la ciudad (Márquez, 2010, 147-148).

Por su parte, en el otro extremo conocido de esta necrópolis (Plaza Ivonne Cazenave), este programa arquitectónico estuvo representado por el alzamiento de una serie de recintos funerarios destacados por su grandiosidad visual, con cuya construcción no sólo se otorgaba calidad monumental a este espacio sacro, sino que se emprendía una importante obra destinada a cobijar y proteger a las sepulturas practicadas en su interior de las continuas arrolladas experimentadas en esta necrópolis ${ }^{6}$.

De todas ellas la que llama especialmente la atención es el denominado acotado imperial (Fig. 4). Concebido con carácter monumental, su fin fue acondicionar su espacio interior de cara a la práctica de sepulturas individuales directamente sobre el firme. Concretamente, y en oposición a las incineraciones que se practicarían para estas fechas en los recintos funerarios anteriormente analizados, las primeras deposiciones al interior de este espacio consistieron en inhumaciones bajo cubierta de tégulas entre mediados del siglo I d. C. mediados del II d. C., las cuales aparecían asociadas espacialmente a un estructura de sillares de morfología piramidal $^{7}$ (Gómez et alii, 2003, 658; De Haro, Cas-

6 La topografía sobre la que se asentó esta necrópolis estuvo caracterizada por un horizonte de elevaciones (o cabezos) constituidos de arenas y arcillas con cobertura de gravas bastante deleznables (Mayoral, 1990), lo que suponía una intensa dinámica erosiva, traducida en un continuo cambio topográfico del paisaje circundante a corto plazo.

7 Una estructura de similares características a ésta fue documentada en el solar de la c/ San Andrés nº y c/Plácido Bañuelos n ${ }^{\circ} 4-6$ (García y Delgado, 2001). No obstante, lo reducido del área de intervención, unido a la no identificación de esta estructura impidieron conocer la posible existencia de tumbas 


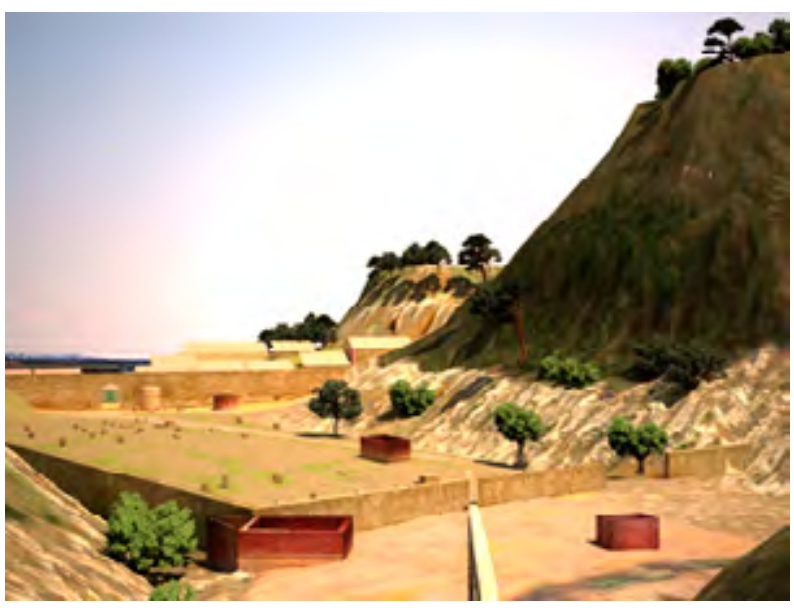

Fig. 6. Reconstrucción en 3D del acotado imperial.

tilla y López, 2006, 583), situada junto a la vía que cruzó de norte a sur toda la necrópolis (Fig. 5). En este sentido, la elección de esta práctica ritual, así como la presencia de este tipo de estructuras está más que atestiguada en ciudades como Carmo o Baelo Claudia, donde la pervivencia de la inhumación como rito de enterramiento se atribuye al fuerte sentimiento de etnicidad que su población demostró de cara a la muerte (Bendala, 1995, 282; Sillières, 1997, 201). Si bien, existe la corriente que aboga por un influjo suritálico de fuerte tradición helenística llegado a la península de la mano de los primeros colonos (Vaquerizo, 2002a, 151), interpretación en la que se incluye la sepultura de Zoísmo documentada en Emerita Augusta ${ }^{8}$, morfológicamente similar al monumento escalonado existente en esta necrópolis (Nogales y Márquez, 2002, 134). No obstante, la documentación de un importante horizonte cultural fenopúnico/turdetano previo a la llegada de los primeros colonos en la ciudad de Onoba y su área de influencia, nos lleva a decantarnos por una continuidad de las tradiciones ya existentes, y no por un influjo importado, lo cual no excluye que éstas se viesen revitalizadas con motivo de la llegada de estos contingentes poblacionales.

Con el cambio de centuria se asiste a la coexistencia de ambos ritos funerarios ${ }^{9}$, si bien mientras

en su área próxima. Sin embargo, su ubicación marca el margen oriental de la vía sepulcral que debió cruzar esta necrópolis.

8 Debemos especificar que a diferencia de la sepultura de Zoismo, el monumento escalonado de esta necrópolis no contenía enterramiento alguno ni en su interior, ni bajo ella.

9 Nos referimos a las tumbas practicadas al interior del acotado, pues como ya se ha comentado, enterramientos de incineración se venían practicando en el interior de los diferentes que las inhumaciones se siguen practicando en el mismo espacio, las incineraciones se organizan en torno a dos áreas funerarias diferenciales. De ellas, la primera se ubica en el extremo noreste del acotado, compuesta por cinco enterramientos con cubierta de tégulas en la mayoría de los casos, y un menaje funerario conformado tanto por elementos rituales, como por objetos de adorno personal (Gómez et alii, 2003; De Haro, Castilla y López, 2006, 585). Frente a ésta, la segunda área localizada en el espacio central estuvo configurada por nueve tumbas definidas mayoritariamente, y en exclusividad, por la fosa de cremación y las propias cenizas del difunto, acompañadas excepcionalmente por un ajuar de escasa calidad compuesto por alguna pieza de cerámica común, a excepción de una de las sepultura de la que se recuperó una moneda de bronce (Gómez et alii, 2003; De Haro, Castilla y López, 2006, 585).

A pesar de estas diferencias rituales, ambos grupos debieron darse de manera simultánea a lo largo del siglo II d. C., donde enterrarse en uno u otro sector vendría de la mano del poder adquisitivo de la persona finada. Concretamente, el área noreste sería la elegida por los individuos más preeminentes dentro del elenco social allí sepultado, al presentar su última morada una imagen exterior cuidada, así como un menaje funerario destacado en objetos personales. Frente a ellos, los individuos económicamente menos solventes se vieron obligados a optar por una tipología y ritual menos ostentoso, emplazando sus sepulturas en un espacio que a todas luces debió resultar poco atractivo al ubicarse sobre un antiguo paleocauce, razón por la cual, además de verse constantemente arrasados por las arroyadas, debieron sufrir una mayor concentración al ser un área altamente demandada (Fig. 6).

En resumen, si por algo se definió el mundo funerario articulado al interior de este acotado fue por la existencia de un paisaje sepulcral abigarrado en torno a tres áreas deposicionales pese a la existencia de grandes espacios libres de enterramientos. No obstante, esta característica no es exclusiva de este espacio cementerial dado que en esta misma línea se encuentra la necrópolis oriental de Baelo Claudia, donde se observa cómo las sepulturas más antiguas, generalmente cremaciones, aparecen agrupados sin delimitar un paisaje funerario orde-

recintos funerarios, así como en sus proximidades desde al menos el cambio de Era. 
nado en torno a vías funerarias, lo que en palabras de sus investigadores recuerda a las necrópolis púnicas y a las primeras afrorromanas, cuyas tumbas aparecían agrupadas en el interior de un espacio visualmente delimitado por una pequeña cerca, caso de Tingis o el Cabo Espartel en Marruecos (Muñoz, García y Prados, 2009, 67-68). Del mismo modo, otra característica de esta necrópolis baelonense es la disposición de sepulturas en distintos sectores separados por grandes espacios estériles, probablemente reflejo post mortem de unidades gentilicias o familiares -quizás étnicoidentitarias-, que pudieron constituir el sistema de agrupamiento tradicional de los habitantes de Baelo Claudia en ese periodo (Muñoz, García y Prados, 2009, 70).

Tampoco debemos ignorar la existencia de una práctica ritual atípica a las necrópolis romanas de éste momento como es la ausencia de terra sigilla$t a$ en sus ajuares (Vidal y Campos, 2006, 27), los cuales estuvieron constituidos por piezas de cerámica común; en ocasiones imitaciones de paredes finas; lucernas, ungüentarios, y de manera destacada, elementos de adorno personal. Esta misma situación se aprecia en otras necrópolis de clara influencia púnica, caso de la existentes en la ciudad de Gades, donde los ajuares de las sepulturas tanto de inhumación como de cremación estuvieron compuestos por joyas (pendientes, anillos, collares, pulseras...), amuletos, objetos de tocador y monedas, las cuales al igual que en nuestro caso resultaron poco frecuentes, en su mayoría pertenecientes al periodo comprendido entre la segunda mitad del siglo I y la primera del siglo II d. C. (Gómez, 2007, 61-ss.), o en la propia ciudad de Carmo, donde se aprecia el no seguimiento de rituales y fórmulas propiamente romanas como sugiere la ausencia generalizada de monedas, o la sistemática marginación del uso de sigillatas por la preferencia de formas de gusto tradicional (Bendala, 2002, 142-ss.).

Más allá del acotado imperial, el paisaje de este sector de la necrópolis estuvo definido por la presencia de cuatro recintos funerarios ${ }^{10}$. El primero de ellos; ubicado en el extremo noreste; posee una planta de tendencia triangular adecuada a la orografía del terreno. Aunque su morfología difiere del común, por norma general de tendencia rectangu-

10 Estos recintos funerarios se corresponden con el denominado Edificio 240 (Gómez et alii, 2003 y De Haro, Castilla y López, 2006), a nuestro parecer correspondiente a tres construcciones independientes, con usos y cronologías diferentes. lar o cuadrangular, en ocasiones este tipo de construcciones fue demandado por las exigencias urbanísticas de las necrópolis, ya fuera por el trazado de una vía, o como en nuestro caso, por cuestiones topográficas -Fig. 7- (Bendala, 1972, 234; Rodríguez, 1991, 62).

Con posterioridad, y aprovechando uno de los paramentos ya existentes de la anterior edificación, se levantó un nuevo recinto con una extensión aproximada de unos $80 \mathrm{~m}^{2}$-Fig. 8- (1000 p.c). Sus medidas, superiores a las documentadas en otros acotados existentes en Hispania, lo convierten en un caso excepcional escasamente constatado en otras ciudades romanas (Rodríguez, 1991, 77), concebido o bien como un cementerio público en sí mismo, dentro del cual se distinguirían secciones más pequeñas de enterramiento (Purcell, 1987, 38), o bien como el terreno adquirido por una familia de gran poder económico o un collegia, destinado en el primer caso a cobijar las sepulturas de todos sus miembros; incluidos esclavos y libertos; y en el segundo a todos sus socios (Donati, 1965, 94).

Según los restos constatados ambos edificios debieron ser construidos en época republicana, para

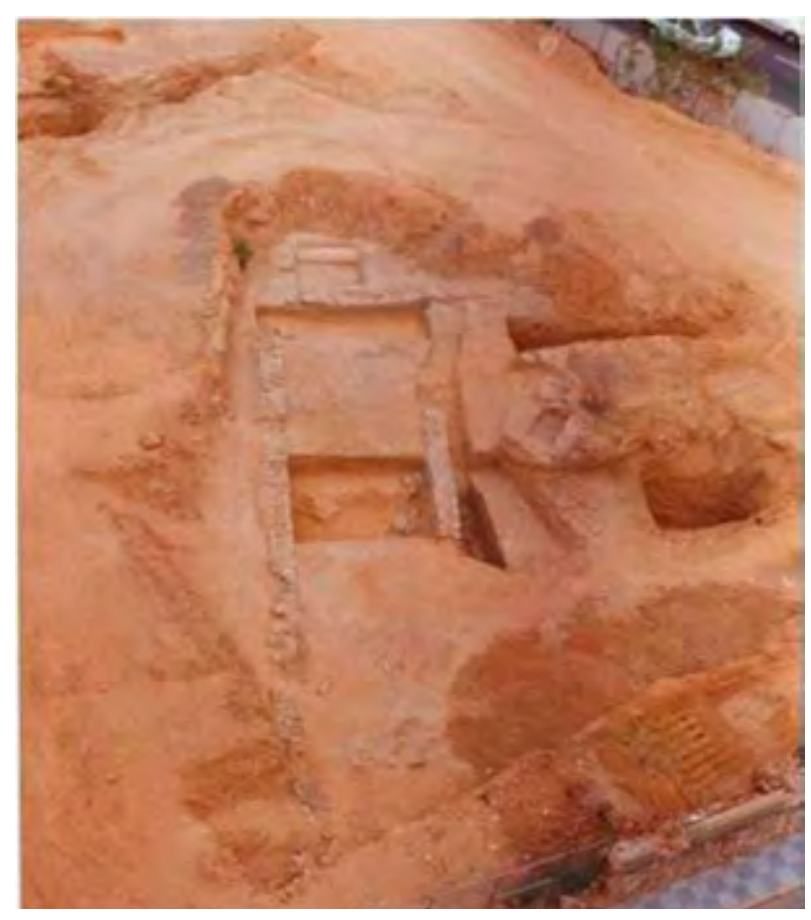

Fig. 7. Recintos funerarios ubicados al noreste del acotado imperial (Foto cedida por la empresa privada de arqueología G.I.R.H.A.). 


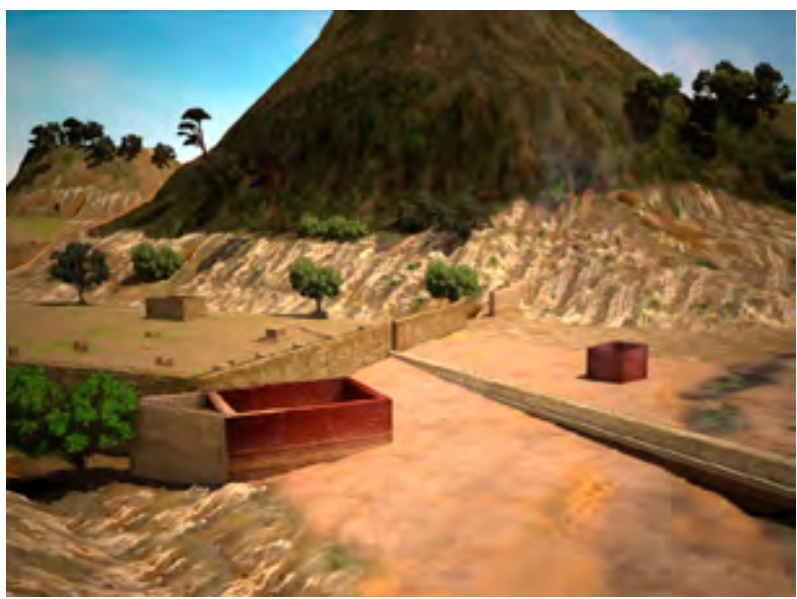

Fig. 8. Reconstrucción 3D de los recintos funerarios.

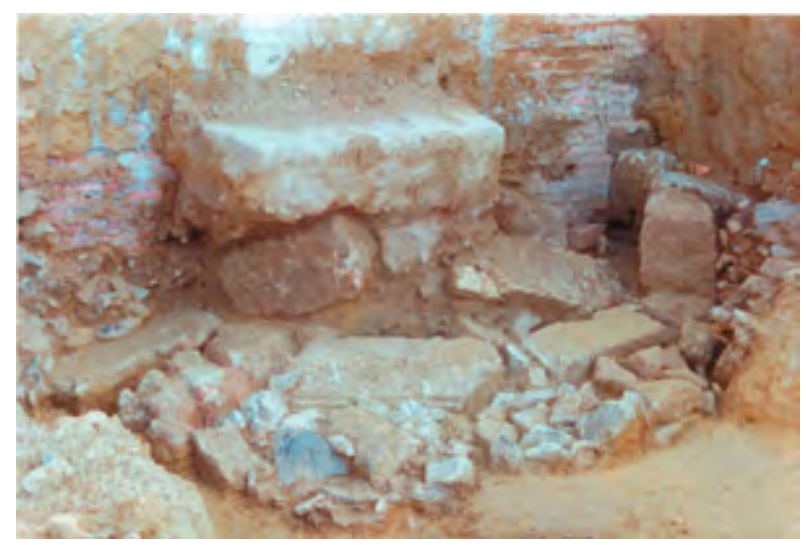

Fig. 9. Monumento circular de sillares de la Plaza Ivonne Cazenave (Foto cedida por la empresa privada de arqueología G.I.R.H.A.).

alcanzar su momento de mayor esplendor entre mediados del siglo I d. C. principios del II d. C., fecha a partir de la cual serían abandonados y amortizados como consecuencia de la construcción de uno de los ramales del acueducto que abasteció de agua a la ciudad. Aunque no se han podido documentar sepulturas en el interior de ninguno de los dos, la intensa vida ritual no deja lugar a dudas sobre su uso funerario, posiblemente destinados a la deposición de cremaciones en urnas ${ }^{11}$.

Entrado el siglo II d.C. se adosaría a este conjunto un nuevo recinto por el extremo septentrional

11 Algunas de estas urnas han sido localizadas entre los cascotes empleados en la cimentación del edificio circular de época bajoimperial. Su presencia supone la existencia de una nueva opción de enterramiento distinta a la desarrollada en el interior del acotado imperial, así como la posible existencia de espacios/ cementerios independientes, con ritos y costumbres diferentes. que vendría a coincidir con la evolución ideológica de estos espacios desde simples construcciones concebidas con el doble objetivo de proteger y resaltar las tumbas de su interior, hacia sepulturas monumentales en sí mismas (Vaquerizo, 2002b, 170-171). De hecho, la existencia de esta construcción supone una respuesta a la ubicación de uno de los enterramientos más suntuosos de esta necrópolis, en cuanto a tipología y ritual, fuera de los límites establecidos por el acotado imperial ${ }^{12}$.

El cuarto de estos recintos, ubicado en contraposición a los anteriores en la margen occidental de la vía que atravesó esta necrópolis, contó con una planta rectangular de unos $10 \mathrm{~m}^{2}$ (Gómez et alii, 2003, 660; De Haro, Castilla y López, 2006, 580). Aunque en un primer momento fue fechado en el siglo III d. C. por emplear una edilicia de ladrillos distinta a los anteriores (Gómez et alii, 2002, Inédito; De Haro, Castilla y López, 2004, Inédito), sus restos materiales nos hablan de una construcción emprendida hacia el cambio de Era, probablemente planeado dentro del programa de monumentalización que venimos comentando.

Del mismo modo, aunque las evidencias recogidas en la memoria de investigación resultan escasas y bastantes confusas, se habla de la existencia de un paramento de sillares sobre cimentación de pizarras al interior del acotado imperial (Amo, 1976, 97), casi con toda probabilidad perteneciente a un recinto funerario desmontado en época bajoimperial para proveer de materiales al monumento circular levantado en sus proximidades. Aunque se desconoce su fecha de construcción, ésta debió ser algo más tardía que la aportada para las dos primeras edificaciones, dado que los recintos de sillería evolucionarían desde los de mampostería y tapial hacia mediados del siglo I d. C. (Ruiz, 2007, 57).

En época bajoimperial, concretamente hacia mediados del siglo II d. C., tendría lugar la última gran remodelación constructiva de esta necrópolis consistente en la edificación de un nuevo acotado funerario algo más al sur que el anterior, precedido por un monumento de sillares de planta circular, última manifestación del poder de una élite urbana que comenzaba ya su declive.

Concretamente, ésta última sepultura monumental contó con un cuerpo principal de sillares de calcarenita dispuestos a soga y tizón, del que se conser-

12 A partir del siglo II d. C. todas las sepulturas serían practicadas al interior del acotado imperial. 
vaban un total de cinco tongadas con una longitud mínima de $4,50 \mathrm{~m}$ y una anchura de $1,90 \mathrm{~m}$, rodeado a nivel de cimentación por un potente anillo de materiales constructivos que le conferían una gran solidez ${ }^{13}$-Fig. 9- (De Haro, Castilla y López, 2006, 581). Todos sus elementos pétreos fueron reaprovechados de otras edificaciones ${ }^{14}$, de ahí que presentara diferentes tratamientos como adintelamientos y molduras en bajorrelieves, así como marcas de cantería y estrías verticales en los materiales utilizados en su cimentación (De Haro, Castilla y López, 2006, 582; De Haro, Castilla y López, 2004, Inédito).

Por su parte, el nuevo acotado nacería de la necesidad de prolongar el uso de este espacio como necrópolis una vez agotado funcional y espacialmente el imperial como consecuencia de las constantes arrolladas, en cuyo interior se experimentaría una progresiva evolución de las tumbas impulsada por las diversas transformaciones que se estaban produciendo en los esquemas socioeconómicos del momento. En este sentido, las sepulturas más tempranas se corresponden con las localizadas en las proximidades del paramento norte de esta edificación, continuación tipológica y ritual de las practicadas en época altoimperial (Gómez et alii, 2003, 658; De Haro, Castilla y López, 2006, 582).

Localizadas al sur de éstas se documentarían tres sepulturas de inhumación, dos de ellas en los límites de la Plaza Ivonne Cazenave (De Haro, Castilla y López, 2006, 583) y la otra en la c/Plácido Bañuelos fechadas en la primera mitad del siglo III d. C. (Amo, 1976, 92). En este caso su tipología y ritualidad suponen una evolución con respecto al esquema anterior, al constatarse una nueva forma de enterramiento consistente en cajas de ladrillos o tégulas, así como por una sustitución del rito de la cremación por el de la inhumación, del que además vendría de la mano una reducción del número de piezas que conformarían el ajuar.

13 Sólo se ha podido conocer un tercio del total de la estructura por aparecer justo en la medianera de dos solares. Pese a ello, sabemos que el resto de la edificación debió desaparecer en la década de los 70 destruida durante el vaciado del solar de la c/ Onésimo Redondo (actual Plácido Bañuelos), ya que a la llegada del equipo sólo se encontraron numerosos materiales constructivos dispersos en superficie correspondientes probablemente a esta edificación, al recinto bajoimperial, así como a las posibles tumbas que éste pudiese haber albergado en su espacio interior (Amo, 1976).

14 Posiblemente, y como ya comentamos líneas más arribas, procedentes del recinto de sillares de época altoimperial ubicado a escasos metros de esta nueva construcción.
El último episodio de este recinto estuvo representado por las sepulturas localizadas en el solar de la c/Plácido Bañuelos en la década de los 70, definidas por un amplio abanico tipológico en el que se incluyen desde las estructuras de tégulas empleadas durante los siglos altoimperiales, hasta las cajas de ladrillos y los enterramientos infantiles en ánfora -Fig. 10- (Amo, 1976, 93-ss.). A pesar de que la tónica general de esta última fase fue la práctica desaparición de los elementos de ajuar del interior de las sepulturas, la aparición de algunas piezas permiten fechar esta última fase entre mediados del siglo IIIIV d. C.

En definitiva, la necrópolis norte de la ciudad de Onoba inició su andadura en época republicana con un área cementerial extendida desde los pies de la muralla de época protohistórica, hasta el extremo más septentrional documentado en la Plaza Ivonne Cazenave. A pesar de ello, desconocemos el patrón de concentración de las sepulturas, así como su dispersión a lo largo del espacio, circunstancia ésta que sólo futuras intervenciones podrá dilucidar. En cualquier caso, estamos en condiciones de hablar de una primera fase comprendida entre finales del siglo II a.C.-mediados del I a. C., caracterizada por la presencia de enterramientos de incineración en fosa carentes de ajuar, asociadas a una estructura muraria probablemente perteneciente a un recinto funerario. En este sentido, y a pesar del mal estado

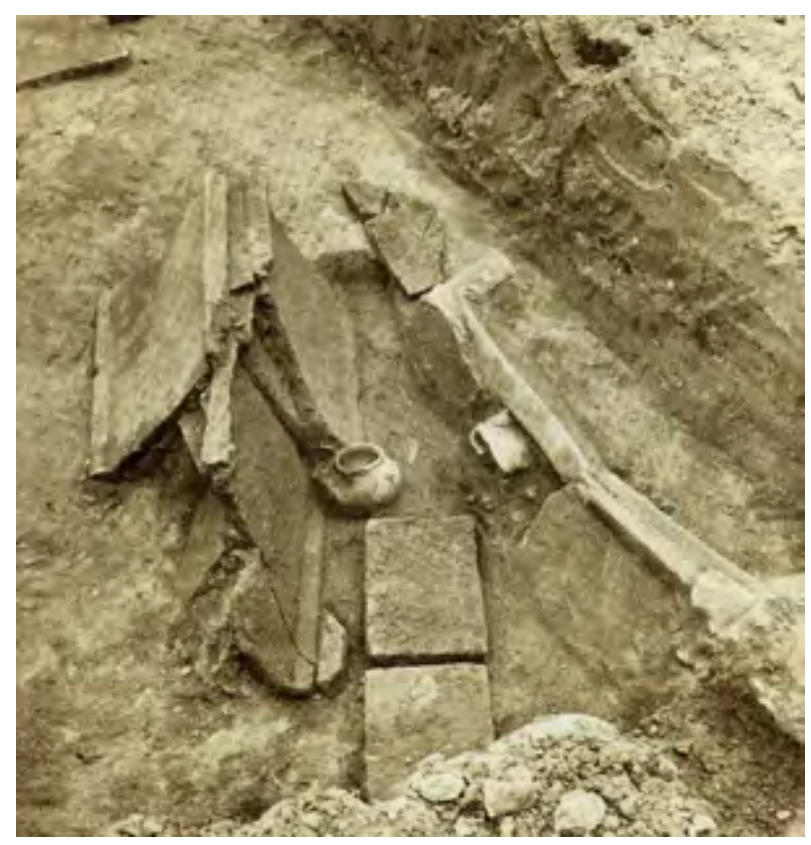

Fig. 10. Tumbas bajoimperiales excavadas en los años 70 en la calle Plácido Bañuelos (Amo, 1976, Lám. 14). 
de conservación de los restos como consecuencia de la amortización del espacio a lo largo de los siglos, se puede observar como desde el primer momento se importaron modelos de enterramientos romanos procedentes de las provincias occidentales.

Será ya hacia mediados del siglo I a. C. cuando este horizonte de contacto alcance su cenit con la ejecución de un importante programa arquitectónico que vendría a reflejar el influjo cada vez mayor de Onoba en el panorama económico del Imperio, otorgándole a la ciudad de los muertos una imagen monumental acorde con la evolución que se estaba experimentando en la ciudad de los vivos. $\mathrm{Si}$ bien, frente a esa imagen exterior monumental basada en patrones heredados de la tradición romana, tales como los recintos funerarios o el monumento de planta circular, nos encontramos con la existencia de una ritualidad mucho más personal e íntima cargada de perduraciones de una cultura previa, de cuyo contacto nacería una nueva realidad funeraria que caracterizaría este extremo de la provincia Baetica. En este sentido, debemos hablar de la coexistencia ritual de incineraciones e inhumaciones durante los siglos altoimperiales, así como la exclusión consciente de sus ajuares de una pieza tan significativa como era en el momento la terra sigillata, sustituida por imitaciones en cerámica común y objetos de adorno personal, más próximas a la tradición púnica detectada en necrópolis como la de Carmo, Baelo Claudia o Gades.

Ya en época bajoimperial, aunque la necrópolis se vio mermada estilísticamente por la crisis económica siguió gozando de una imagen monumental cimentada en modelos de enterramientos típicamente romanos, localizados a partir de este momento al sur de la Plaza Ivonne Cazenave como consecuencia de la progresiva reducción de la extensión de la ciudad por la caída de gran parte de su entramado económico. Al margen de ello, a nivel ritual la llegada del cristianismo impondría de manera exclusiva la inhumación, así como una progresiva reducción del número de piezas incluidas en los ajuares.

\section{BibLIOGRAFíA}

Amo y de la Hera, M. Del (1976), Restos materiales de la población romana de Onuba, Huelva Arqueológica, II, Madrid.

Beltrán Fortes, J. (2000), "Mausoleos romanos de Torreparedones (Castro del Río/Baena, Córdo- ba), sobre la tumba de los Pompeyos y otro posible sepulcro monumental", Habis, 31, 113-136.

(2002), "La arquitectura funeraria en la Hispania meridional durante los siglos II a. C.-I d. C.”, Espacios y usos funerarios en el Occidente Romano, vol. II (Vaquerizo Gil, D., Ed.), Córdoba, 233-258.

Bendala Galán, M. (1972), "Los llamados columbarios de Mérida”, Habis, 3, 223-253.

(1995), "Necrópolis y ritual funerario en la Hispania Alto-Imperial”, Arqueoloxia da Morte na Península Ibérica desde Orixes ata o Medievo, Xinzo de Limia, 277-290.

(2002), "Perduraciones y romanización en Hispania a la luz de la arqueología funeraria, notas para una discusión", Archivo Español de Arqueología, 75, 137-158.

Campos, J. M., Vidal, N. y Ruiz, J. M. (2010), "Acerca de la condición jurídica de Onoba Aestuaria", Pyrenae, 41/1, 50-75.

Ciurana, J. y Macías, J. M. (2010), "La ciudad extensa, usos y paisajes suburbanos de Tarraco", Las áreas suburbanas en la ciudad histórica. Topografía, usos, función (Vaquerizo, D., Ed.), Monografías de arqueología cordobesa, 18, Córdoba, 309-334.

De Haro, J., Castilla, E. y López, M. Á. (2004), Intervención arqueológica de urgencia en la Plaza Ivonne Cazenave $n^{\circ} 1$ (Huelva). Control arqueológico sobre vaciado del solar. $4^{o}$ y $5^{\circ}$ fase de actuación. Memoria científica, Vol. I-II, Delegación Provincial de Cultura. Junta de Andalucía, Inédito.

(2006), "Intervención arqueológica en Plaza Ivonne Cazenave $\mathrm{n}^{\mathrm{O}} 1$ (Huelva). $4^{\mathrm{O}}$ y $5^{\mathrm{o}}$ fase de actuación”, Anuario Arqueológico de Andalucía/2003, III, 577-587.

De Haro, J., López, M. Á. y Castilla, E. (2007), Intervención arqueológica preventiva en Plaza Ivonne Cazenave $n^{\circ} 1$ (Huelva). $6^{a}$ fase de actuación. Excavación previa a la consolidación e integración de restos emergentes en el sector III. La plaza arqueológica. Memoria científica, Delegación Provincial de Cultura. Junta de Andalucía, Inédito.

Donati, A. (1965), "Cippi e misure dei sepolcreti romani de Bologna”, Strenna Storica Bolognese, $X V, 89-97$.

García Fernández, M. y Delgado Domínguez, A. (2001), Memoria de Intervención Arqueológi- 
ca de Urgencia. Excavación Comprobatoria Solar c/San Andrés $n^{\circ} 5$ y Plácido Bañuelos $n^{o}$ 4-6. Memoria científica, Delegación Provincial de Cultura, Junta de Andalucía, Inédito.

Gómez Fernández, V. (2007), Una aproximación al estudio de la necrópolis del Gades Altoimperial, Trabajo de Investigación Inédito, Cádiz.

Gómez, F., Campos, J. M., Beltrán J. A., López, M. Á. y Gómez, Á. (2002), Intervención arqueológica de urgencia en el solar Plaza Ivonne Cazenave, 1 (Huelva). Memoria Científica, Delegación Provincial de Cultura, Junta de Andalucía, Inédito.

Gómez, F., López, M. Á.; Beltrán, J. M., Gómez, Á., y Campos, J. M. (2003), "Intervención arqueológica en el solar Plaza Ivonne Cazenave, 1 (Huelva)", Anuario Arqueológico de Andalucía / 2000, III, 577-587.

González, B. y Guerrero, O.(2008), Memoria científica de la intervención arqueológica de urgencia en el solar de Plaza San Pedro 4-5 de Huelva, Delegación Provincial de Cultura, Junta de Andalucía, Inédito.

González, B., Guerrero, O. y Echevarría, A. (2006), "Intervención arqueológica de urgencia en Plaza de San Pedro no 4-5 de Huelva", Anuario Arqueológico de Andalucía/ 2003, III, 543-549.

Hesberg, H. Von (1994), Monumenta. I sepolcri romani e la loro archittetura, Milano.

Márquez Pérez, J. (2006), Los Columbarios, arquitectura y paisaje funerario en Augusta Emerita, Ataecina, Instituto de Arqueología de Mérida, Colección de estudios históricos de la Lusitania, Mérida.

Mayoral Alfaro, E.J. (1990), "Geología de la depresión inferior del Guadalquivir”, El Cuaternario en Andalucía Occidental, Aequa Monografías, 1, Sevilla, 7-20.

Muñoz Vicente, A., García Jiménez, I., y Prados Martínez, F. (2009), "Espacios jerarquizados y áreas funerarias en la necrópolis oriental de Baelo Claudia (Tarifa, Cádiz). Nuevas perspectivas de estudio, Jorge Bonsor y la recuperación de Baelo Claudia (1917-1921)", Catálogo de la Exposición celebrada en el Conjunto Arqueológico de Baelo Claudia entre el 4 de junio y el 30 de septiembre de 2009, Sevilla, 59-77.

Murillo, J. F. y Carrillo, J. R. (1999), “Aspectos de la monumentalización de la necrópolis de Colonia Patricia. El monumento funerario de Puerta de Gallegos”, Ciudades privilegiadas en el
Occidente Romano (González, J., Ed.), Serie Historia y Geografía, 42, Sevilla, 365-378.

Nogales, T. y Márquez, J. (2002), "Espacios y tipos funerarios en Augusta Emerita", Espacios $y$ usos funerarios en el occidente romano, I (Vaquerizo, D., Ed.), Córdoba, 113-144.

O’kelly Sendrós, J. (2012), Figlina romana. Producción y comercio cerámico en el territorio onubense, Tesis Doctoral, Universidad de Huelva, Inédita.

Purcell, N. (1987), "Tomb and Suburb”, Römische Gräberstrassen. Selbstdarstellung-Status-Standard (Von Hesberg, H. y Zanker, P., Eds.), München, 25-41.

Rodríguez Neila, J. F. (1991), "Espacios de uso funerario con indicación de medidas en las necrópolis romanas", Conimbriga, XXX, 59-94.

Ruiz Osuna, A. B. (2005), "La via sepulchralis occidental, un ejemplo de monumentalización funeraria en Colonia Patricia”, Anales de Arqueología Cordobesa, 16, 79-104.

(2007), La monumentalización de los espacios funerarios en Colonia Patricia Corduba (Ss. I a. C.-II d. C.), Colección Arqueología Cordobesa, 16, Córdoba.

Sacchi, F.(2003), Ianua leti, l'architettura funeraria di Milano romana, Milano.

Sillières, P. (1997), Baelo Claudia. Una ciudad romana de la Bética, Madrid.

Vaquerizo Gil, D. (2002a), "Espacios y usos funerarios en Corduba”, Espacios y usos funerarios en el Occidente Romano, vol. II (Vaquerizo Gil, D., Ed.), Córdoba, 141-200.

(2002b), "Recintos y acotados funerarios en Colonia Patricia Corduba”, Madrider Mitteilungen, 43, 168-206.

Vaquerizo, D. y Murillo, J. F. (2010), "Ciudad y suburbio en Corduba. Una visión diacrónica (siglos II a. C.-VII d. C.)", Las áreas suburbanas en la ciudad histórica. Topografía, usos, función (Vaquerizo, D., Ed.), Monografías de Arqueología Cordobesa, 18. Córdoba, 455-522.

Vidal, N. de la O. y Campos, J. M. (2006), "Las necrópolis de Onuba”, Anales de Arqueología Cordobesa, 17, II, 13-34.

Zanker, P. (1992), Augusto y el poder de las imágenes, Madrid. 
